\title{
Surface Modification of Titanium Dental Implants: A Review
}

\author{
Rimal $\mathrm{U}^{1 *}$, Joshi $\mathrm{S}^{2}$, Shrestha $\mathrm{P}^{3}$ \\ ${ }^{1}$ Resident, Department of Prosthodontics, National Academy of Medical Sciences, Kathmandu, Nepal \\ ${ }^{2}$ Professor, Department of Prosthodontics, National Academy of Medical Sciences, Kathmandu, Nepal \\ ${ }^{3}$ Tutor, Department of Prosthodontics, National Academy of Medical Sciences, Kathmandu, Nepal
}

\begin{abstract}
Osseointegration of titanium dental implants is the most important clinical parameter for an implant to be successful. One of most biocompatible material, titanium can be made to affix fast on to host bone via various modification of its surface. Machined and smooth titanium implant osseointegrate into living bone tissue but with a roughened surface, this is much more predictable as well as promising clinically. Surface modification allows for an increase in the surface area on to which the osteoblasts easily start laying bone. So, there have been various methods to roughen the surface of titanium implants. The article describes various methods used for modifying the surfaces of dental implants, giving a note on their clinical efficacy as well as advantages and disadvantages of these methods.
\end{abstract}

Key words: Dental Implants, Osseointegration, Wettability

\section{Introduction}

$\mathrm{G}$ eometry and surface topography are crucial for the short and long-term success of dental implants. ${ }^{1}$ Direct bone apposition onto the surface is enhanced with surface treatments of dental implants. Surface treatment is used to modify the surface topography and surface energy, resulting in an improved wettability ${ }^{2,3}$, increased cell proliferation and growth ${ }^{2}$ and accelerated osseointegration process ${ }^{4}$.

There are studies that show the surface roughness of dental implants affects the rate of osseointegration and biomechanical fixation. ${ }^{5,6}$ A study by Brett PM et al that was first of its kind showed that gene expression of osteoblast cells was increased with increase in surface roughness; thereby renaming these genes as roughness genes. ${ }^{7}$ Surface roughness can be divided into three levels depending on the scale of features: macro-, micro- and nano-sized topologies. ${ }^{1}$

\section{*Corresponding Author}

Dr. Ujjwal Rimal

Resident, Department of Prosthodontics, National Academy of Medical Sciences, Kathmandu, Nepal

Email:urimal12345@gmail.com
Macro level pertains to topographical features in range of millimeters to tens of microns. High roughness results in early fixation and long term mechanical stability, ${ }^{8}$ but with increased incidence of periimplantitis and ionic leakage. ${ }^{9}$ The microtopographic profile of implants is in the range of 1-10 $\mu \mathrm{m}$. A theoretical approach suggested that the ideal surface should be covered with hemispherical pits approximately $1.5 \mu \mathrm{m}$ in depth and $4 \mu \mathrm{m}$ in diameter. ${ }^{10}$ Topography in nanometer ranges play important role in adsorption of proteins, adhesion of osteoblastic cells and thus the rate of osseointegration. ${ }^{7}$

This article reviews various methods employed and under research for the modification of implant surface. It also includes examples of different implant systems with their surface modification methods.

\section{Method}

A medline search was done to look for the published articles related to the surface modifications of titanium implants. The key words used were "implant surface modification", "biomodification of implant surfaces", 
"dental implants surface modification", "osseointegration", "surface characteristics of dental implants", "plasma spraying of dental implants", "dental implants surface coating", "wettability of dental implants". Among various published articles, those that contained about different ways of modifying implant surfaces were included. Review articles that contained information on effects of surface modification were also included.

\section{Result}

There are different methods to roughen dental implant surfaces. Various surface treatments give different sizes of roughness. Characteristics and topography of implant surfaces played role in rapid osseointegration as well as long term survival of dental implants. Advantages of rougher surface and its effect on the host response were well documented. Various methods to roughen the implant surface have been proposed. Thus this review article highlights some aspects of surface treatments of dental implants enumerating advantages and limitations.

Table: 1 Methods of Surface Treatment of Titanium Dental Implants

\begin{tabular}{|l|l|}
\hline Ablative Procedure & Additive Procedures \\
\hline Grit blasting & Plasma Spraying \\
\hline Acid Etching & Electrophoretic Deposition \\
\hline Anodizing & Sputter Deposition \\
\hline Laser Treatment & Sol Gel Coating \\
\hline & Biomimmetic Precipitation \\
\hline
\end{tabular}

\section{Ablative Procedures}

\section{Grit Blasting}

One route for roughening the surface is grit blasting, through pressurized particle projection either using ceramic materials or silica onto the implant surface. Materials such as sand, hydroxyapatite, alumina, zirconia, $\mathrm{TiO}_{2}$ particles are usually employed for the purpose. Grit blasting is always followed by an acid etching to remove the residual blasting particles. ${ }^{11}$ Depending on the size and shape of these particles, which are polyhedral with sharp corners; and upon their velocity, erosion and material tearing of the titanium surface is inflicted. $^{12}$ (Figure 1) The blasting material should be chemically stable, biocompatible and should not hamper the osseointegration of the titanium implants. ${ }^{1}$

Alumina $\left(\mathrm{Al}_{2} \mathrm{O}_{3}\right)$ is frequently used as a blasting material and produces surface roughness varying with the granulometry of the blasting media. However, the blasting material is often embedded into the implant surface and residue remains even after ultrasonic cleaning, acid passivation and sterilization. Alumina is insoluble in acid and is thus hard to remove from the titanium surface. In some cases, these particles have been released into the surrounding tissues and have interfered with the osseointegration of the implants. Moreover, this chemical heterogeneity of the implant surface may decrease the excellent corrosion resistance of titanium in a physiological environment. ${ }^{13}$

Titanium oxide particles with an average size of $25 \mu \mathrm{m}$ produce a moderately rough surface in the $1-2 \mu \mathrm{m}$ range on dental implants. ${ }^{1}$ A study has reported high clinical success rates for titanium grit-blasted implants, up to 10 years after implantation ${ }^{14}$.

Wennerberg et $\mathrm{al}^{15}$ demonstrated with a rabbit model that grit-blasting with $\mathrm{TiO}_{2}$ or $\mathrm{Al}_{2} \mathrm{O}_{3}$ particles gave similar values of boneimplant contact, but drastically increased the biomechanical fixation of the implants when compared to smooth titanium.

Another possibility for roughening titanium dental implants involves using a biocompatible, osteoconductive and resorbable blasting material. Calcium phosphates such as hydroxyapatite, beta-tricalcium phosphate and mixtures have been considered useful blasting 
materials. These materials are resorbable, leading to a clean, textured, pure titanium surface. ${ }^{1}$

\section{Acid Etching}

Etching with strong acids such as Hydrochloric acid, Sulphuric acid, Nitric acid and Hydrofluoric acid is another method for roughening titanium dental implant surfaces (Figure 2). Acid etching produces micropits with sizes ranging from 0.5 to $2 \mu \mathrm{m} .{ }^{1}$ It increases the subsurface hydrogen concentration and the formation of titanium hydride. This protects the titanium better than unstable surface $\mathrm{TiO}_{2}$ coat which forms immediately on the pure titanium surface exposed to air. ${ }^{16}$

The surface of titanium roughened by acid etching has increased cell adhesion and bone formation thus enhancing osseointegration. ${ }^{11}$ Yukari Iwaya et $\mathrm{al}^{16}$ also concluded that concentrated sulfuric acid etching was a simple and effective way to roughen the surface of titanium without compromising biocompatibility.

Dual acid etching is a method in which titanium implants are treated via chemical or acid whether in sequence or with the combination of both ${ }^{11}$ and also the treatment chemical or acid may be heated prior to treatment. ${ }^{1}$ This treatment produces micro rough surface and is shown to induce rapid osseointegration. ${ }^{11}$

Marco Degidi et al ${ }^{17}$ evaluated two acid etched implants that had been retrieved at 6 months post-insertion in human mandible due to inferior alveolar nerve damage during placement. The case report showed that both implants were surrounded by newly formed bone in low-power magnification. At higher magnification compact bone was found. The bone implant contact percentage for both implants was a mean $61.3 \%$ $( \pm 3.8 \%)$ and newly formed bone showed many viable osteocytes. Thus they concluded that acid etched surface allowed rapid and uneventful osseointegration. The surface was thermal dual acid etched that resulted in a clean, highly detailed surface texture, devoid of entrapped foreign materials and impurities which seem to enhance fibrin attachment to implant surface during clotting process.

SLA surface refers to those implant surfaces that have been acid etched after sand blasting with large grit alumina particles (Figure 3). This remains the most widely used method for surface preparation of a dental implant. SLA has a complex microstructured surface with 20 to $40 \mu \mathrm{m}$ wide cavities, produced by blasting superposed with etched micropits about 0.5 to 3 $\mu \mathrm{m}$ in diameter ${ }^{18}$ and shows hydrophobic nature that host surrounding has to overcome before osteogenic cells are laid upon to start bone synthesis.

SLActive surface as designed by Straumann dental implant systems show increased hydrophilicity compared to that of SLA surface owing to its preparation condition. The modification differs from SLA in that, after acid etching, preparation is done in protective gas condition (Nitrogen gas atmosphere), followed by liquid instead of dry storage. The implant system strongly notes that secondary stability is far more rapid such that early loading may be possible. Schwarz et al ${ }^{19}$ showed that vascular infiltration of blood clot adjacent to implant was apparent for both SLA and SLActive implant types after 1 day of insertion, contacting the surface of SLActive implants but not SLA implants.

Thus this innovative technique of surface modification may be leading to early implant stabilization and loading but this has to be further comprehended by other larger studies.

\section{Anodization}

Porous surface is also produced by galvanostaticanodization of titanium surface in strong acids $\left(\mathrm{H}_{2} \mathrm{SO}_{4}, \mathrm{H}_{3} \mathrm{PO}_{4}, \mathrm{HNO}_{3}, \mathrm{HF}\right)$ at high current 
density $\left(200 \mathrm{~A} / \mathrm{m}^{2}\right)$ or potential $(100 \mathrm{~V})$. When strong acids are used as electrolytes oxide layer will be dissolved along current convection line and thickened in other regions. This dissolution produces micro or nano pores on titanium surface $^{1}$. (Figure 4)

Anodic oxidation results in a thickening of the oxide film, with possible improved biocompatibility of dental implants ${ }^{20}$. The commercially pure $\mathrm{Ti}$ implants generally have an oxide thickness of $17-200 \mathrm{~nm}$ while the anodized implants have an oxide thickness between 600 and $1000 \mathrm{~nm}^{21}$.

In a study conducted by Sul $\mathrm{Y} T$ et $\mathrm{al}^{21}$ the anodized implants demonstrated a greater bone response histomorphometrically than control implants and the osteoconductivity was more pronounced around the anodized implant surfaces. The parameters that differed between the unprepared and anodized implant surfaces, i.e. the oxide thickness, the pore size distribution, the porosity and the crystallinity of the surface oxides may represent factors that have an influence on the histomorphometrical results indicated by a stronger bone tissue response to the anodized implant surfaces, with an oxide thickness of more than $600 \mathrm{~nm}$.

SulYTet $\mathrm{al}^{22}$ in a study that included the anodized surface of titanium concluded that oxide properties of titanium implants, which include oxide thickness, micropore configurations and crystal structures, greatly influence the bone tissue response in the evaluation of removal torque values.

\section{Laser Treatment}

One of the basic criteria for osseointegration is the purity of titanium dental implant surface i.e. no adulteration with other materials is desired ${ }^{23}$. The surfaces obtained by classic methods show irregular non-reproducible patterns and also contaminate surface with materials other than titanium which may interfere with the process of osseointegration ${ }^{24}$. Berardi D et $\mathrm{al}^{24}$ conducted a study to see if laser treatment would produce regular rough surfaces without contamination to find out the hypothesis to be true. Laser treatment may be used for surface alteration for osseintegration or as treatment of periimplantitis. $\mathrm{CO}_{2}$ Laser at lower power seems to be less destructive to grooves and pitches of osseintegrated implants for the treatment of periimplantitis $^{25}$.

\section{Additive Procedures}

\section{Plasma Spraying}

Plasma spraying involves deposition of thick layer of coating materials such as hydroxyapatite and titanium through thermal spray mechanism ${ }^{11}$. Plasma spray substantially increases surface area of implants by increasing the surface roughness ${ }^{26}$.

Titanium plasma-spraying is a method that injects titanium powders into a plasma torch at high temperature that are then projected on to the surface of the implants. Here they condense and fuse together and form a film of about 30 $\mu \mathrm{m}$ thick. The thickness must reach 40-50 $\mu \mathrm{m}$ to be uniform. The coating thus obtained has an average roughness of around $7 \mu \mathrm{m}$ that increases the surface area of titanium implant ${ }^{1}$.

Plasma-spraying of hydroxyapatite ceramic particles includes injection of hydroxyapatite ceramics into plasma torch at high temperature that is projected on to the titanium surface where they condense and fuse together to form a film of thickness ranging from few millimeters to few micrometers. The mechanical retention of this coating is obtained mechanically after roughening the surface with other methods like grit blasting ${ }^{1}$. Several calcium phosphate phases have been observed in plasma-sprayed HA coatings like tricalcium phosphates $(\beta$ and $\alpha$-TCP), tetracalcium phosphate, calcium oxide and amorphous calcium phosphate ${ }^{27}$. The biologic fixation of implants coated with calcium phosphate is faster than that of 
implants with no coating. ${ }^{28}$ However there are some clinical problems with plasma sprayed calcium phosphate coating, the major one being delamination of the coating from implant surface despite its strong attachment to bone ${ }^{1}$. The discrepancy in dissolution of various phases of calcium phosphate in the coating leads to delamination and particle release and thus the clinical failure of dental implants ${ }^{29}$. Also due to the size of dental implants plasma spraying with hydroxyapatite is not predictable ${ }^{1}$.

Ong J L et al ${ }^{27}$ evaluated titanium plasma sprayed and Hydroxyapatite plasma-sprayed implants for bone contact length bone interfacial strength in vivo in dogs' mandible. They concluded that TPS implants exhibited similar pull-out strength compared to HA implant but bone contact length was more for HA implants and this did not affect the interfacial bone-implant strength for both implants.

\section{Electrophoretic Deposition (EPD) of Hydroxyapatite}

EPD is an effective technique for deposition on an electrode charge-carrying particle from a stable colloidal suspension when under the influence of an applied direct current. It is fairly rapid and inexpensive way of producing a dense and uniform coating on substrates even with complex geometries. This method comprises two steps: migration of charged particles in a liquid solvent by the action of an applied electric field (electrophoresis), and the coagulation of particles to form an adherent layer on the electrode(deposition). Coatings produced by this method are known for controlled thickness and morphology. ${ }^{30}$ In EPD of Hydroxyapaptite(HA) on implant surface, colloidal solution of HA on ethanol is generally prepared and deposited on to the implant surface. Coating so obtained is finally sintered at $800^{\circ} \mathrm{C}^{31}$.

\section{Sputter Deposition}

The adhesion of a coating to its substrate and the integrity of the substrate/coating interface are always concerned in determining the performance and reliability of any HA-coated devices. An effective approach in the design of eliminating material-property discontinuities to significantly increase adhesion strength is by means of grading the material composition near the interfaces or through the coatings. The toplayer of coatings may provide good bioactive properties to accelerate bone healing and the underlying bond coat may be designed to achieve maximum adhesion strength. Between these two layers is a transition layer with intermediate properties. This may be achieved with radiofrequency magnetron sputtering methods ${ }^{32}$.

\section{Sol-Gel Coating}

In this method, a sol-gel precursor is prepared that contains reactants which upon heating will produce various forms of hydroxyapatite. This precursor is generally prepared in ethanol in sol stage that will subsequently be converted to gel with specific viscosity by thermal cycling. Titanium implants are then immersed in to this gel and rapidly thermo-cycled (generally to $600^{\circ} \mathrm{C}$ ). Thus a coated surface adhered to titanium is obtained. Repeat coatings and thermocycling is done to obtain desired thickness of coat.

\section{Biomimetic Precipitation}

This technique allows for nucleation and growth of bone-like crystals on a pretreated substrate by immersing it in a supersaturated solution of calcium phosphate under physiological conditions $\left(37^{\circ} \mathrm{C}\right.$ and $\left.\mathrm{pH}=7.4\right)$. In general, two subsequent steps have been used to enhance the heterogenous nucleation of the calcium phosphate. First the implants are treated with an alkaline solution in order to form titanium hydroxyl groups on the titanium surface to serve as nucleating points. In the second step, the coating develops under crystal growth conditions. ${ }^{1}$ This method can be modified for the incorporation of drugs or growth factors onto the implant surface thereby making the implants osteoinductive and osteoconductive. 


\section{Future Trends}

The future trends concern the modifications of surface roughness at the nano-scale level for promoting protein adsorption and cell adhesion, biomimetic calcium phosphate coatings for enhancing osteoconduciton and the incorporation of biological drugs for accelerating the bone healing process in periimplant area ${ }^{1}$.

Research into the dimension of the roughness for cell adhesion is limited. Geometry of the roughness so developed after surface treatment is not reproducible. Pores and pits developed by various methods of treatments range from micrometers to nanometers. In vitro experimental studies ${ }^{33-35}$ have demonstrated that the attachment of osteoblastic cells was enhanced on submicron scale structures but not on smooth surfaces. Well-developed filopodia directly entered nanometer-sized pores. The nanometer structures may also give the cells positive guidance by means of the selective attachments of osteoblasts to the implant surface ${ }^{1}$.

Surface of titanium dental implants may be coated with bone-stimulating agents such as growth factors in order to enhance the bone healing process locally. Member of the transforming growth factor (TGF- $\beta$ ) superfamily, and bone morphogenetic proteins (BMPs), platelet-derived growth factor (PDGF) and insulin-like growth factor(IGF-1 and -2) are some of the promising candidate for this purpose ${ }^{1}$.

The surface of implants can also be loaded with bone modeling molecules like antiresorptive drugs (bisphosphonates) ${ }^{1}$. It has been shown that bisphosphonate surface treated implants increased bone density locally ${ }^{36}$.

Table 2: Examples of various surface treatment methods of different dental implant systems

\begin{tabular}{|c|c|}
\hline Surface Treatment & Implant System / Surface \\
\hline $\begin{array}{l}\text { Acid-Etched } \\
\text { Etching with strong acids increases the surface roughness and the } \\
\text { surface area of titanium implants }\end{array}$ & $\begin{array}{l}\text { BIOMET } 3 \text { i OSSEOTITE } ® \text { and } \\
\text { NanoTite }^{\mathrm{TM}}\end{array}$ \\
\hline $\begin{array}{l}\text { Anodized } \\
\text { This electrochemical process roughens titanium oxide layer }\end{array}$ & Nobel BiocareTiUnite ${ }^{\circledR}$ \\
\hline $\begin{array}{l}\text { Blasted } \\
\text { Particles are projected through a nozzle at a high velocity onto } \\
\text { the implant. Various materials like titanium dioxide, aluminium } \\
\text { dioxide and hydroxiapatite (HA) are used. }\end{array}$ & $\begin{array}{l}\text { DENTSPLY Implants ASTRA TECH } \\
\text { TiOblast }{ }^{\mathrm{TM}} \text {, Zimmer Dental MTX }{ }^{\mathrm{TM}} \text {, } \\
\text { Inclusive }{ }^{\circledR} \text { Tapered Implants }\end{array}$ \\
\hline $\begin{array}{l}\text { Blasted and acid-washed/etched } \\
\text { Implants undergo a blasting process. Afterward, the surface is } \\
\text { etched with strong acids. }\end{array}$ & $\begin{array}{l}\text { CAMLOG Promote } ₫ \text {, DENTSPLY } \\
\text { Implants FRIALIT }{ }^{\circledR} \text { and } \\
\text { FRIADENT }{ }^{\circledR} \text { plus, Straumann }{ }^{\circledR} \\
\text { SLA } ®\end{array}$ \\
\hline $\begin{array}{l}\text { Hydroxyapatite (HA) } \\
\text { HA is an osteoconductive material that has the ability to form a } \\
\text { strong bond between the bone and the implant. }\end{array}$ & $\begin{array}{l}\text { Implant Direct (various), Zimmer } \\
\text { Dental MP-1® }\end{array}$ \\
\hline $\begin{array}{l}\text { Laser Ablation } \\
\text { High-intensity pulses of a laser beam strike a protective layer that } \\
\text { coats the metallic surface. As a result, implant demonstrates a } \\
\text { honeycomb pattern with small pores. }\end{array}$ & BioHorizons ${ }^{\circledR}$ Laser-Lok ${ }^{\circledR}$ \\
\hline $\begin{array}{l}\text { Plasma-sprayed } \\
\text { Powdery forms of titanium are injected into a plasma torch at } \\
\text { elevated temperatures. }\end{array}$ & $\begin{array}{l}\text { Straumann }{ }^{\circledR} \text { ITI }{ }^{\circledR} \text { titanium plasma- } \\
\text { sprayed (TPS) }\end{array}$ \\
\hline
\end{tabular}




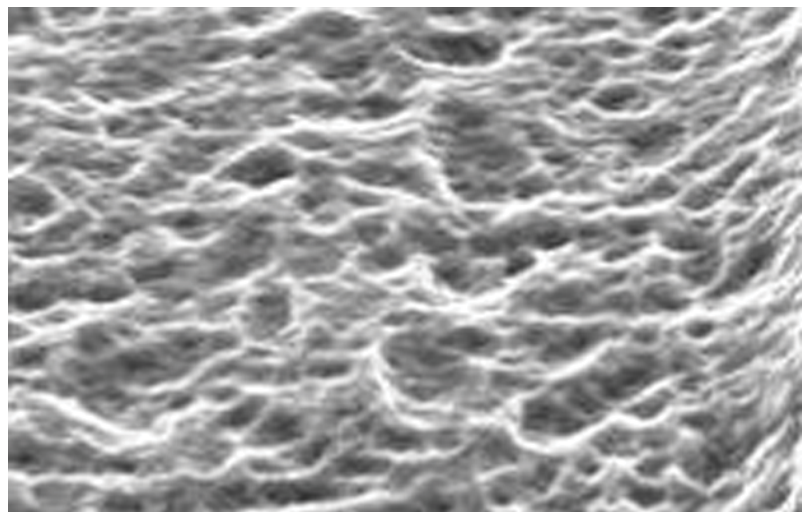

Figure 1: Scanning electron micrograph of grit blasted titanium surface. ${ }^{38}$

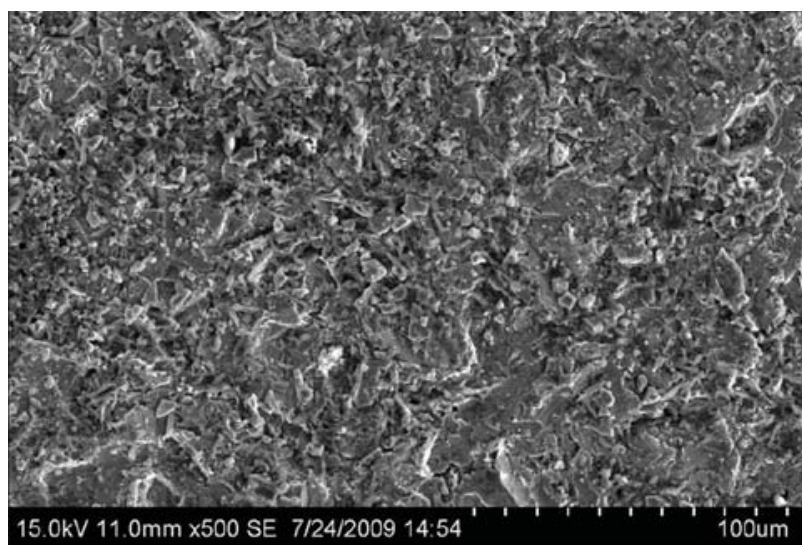

Figure 3: Scanning electron micrograph of SLA titanium surface. ${ }^{39}$

\section{Discussion}

Surface modification of dental implants either via ablative or additive procedures result in such surface properties that enhance osseointegration. Coating of implant surfaces provides with good mechanical properties but are with certain limitations like poor long term adherence of coating ${ }^{37}$, non-uniformity in thickness of the deposited layer ${ }^{1}$ and variation in crystallinity and composition of the coating ${ }^{27}$. But understanding the suitable parameter during plasma spraying is important to control some of these limitations. Blasting a surface to increase the surface roughness is an accepted procedure and is also employed for surface treatments of dental implants. The resulting surface roughness dimension depends on particle size of the blasting medium. Alumina show adherence onto the titanium surface after blasting that has

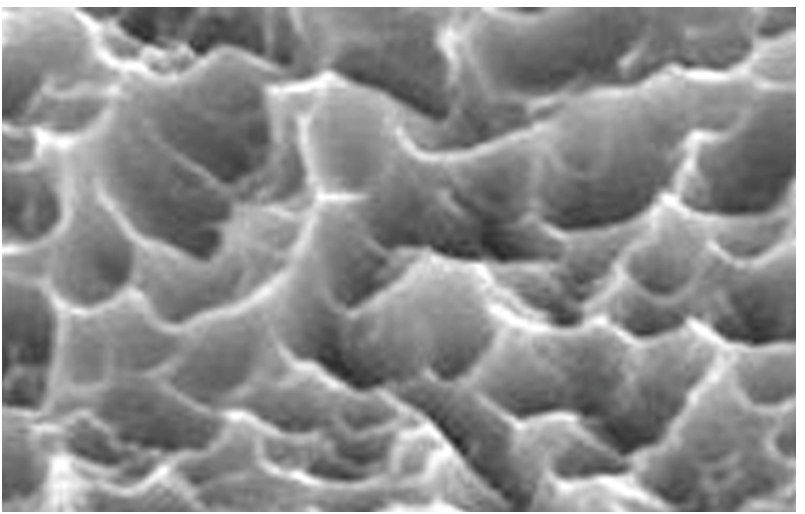

Figure 2: Scanning electron micrograph of Acid etched titanium surface. ${ }^{38}$

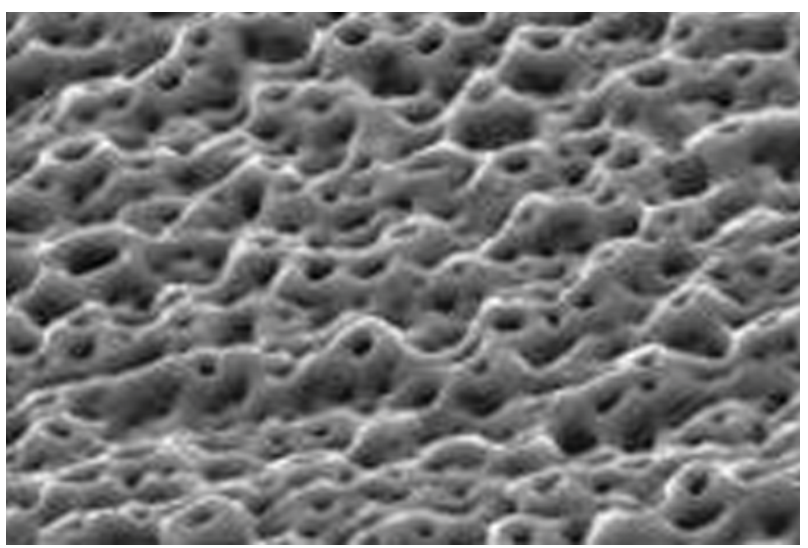

Figure 4: Scanning electron micrograph of Anodized titanium surface. ${ }^{38}$

been shown to leach into the surrounding host tissue interfering osseointegration ${ }^{13}$. Titanium oxide blasting however have shown long term predictable outcomes in terms of survival ${ }^{13}$.

Currently surface roughening via grit blasting and acid etching and coating with hydroxyapatite are commonly used techniques in practice. Both methods have advantages as well as limitations.

Numerous scientific papers have shown that rougher implant surfaces have greater bone implant contact (BIC) than that of smooth surfaces. BIC is a very important parameter for long term survival of the implants.

Newer methods are being introduced to enhance the surface properties of dental implants. The ideal implant would be to have such surface that increases the likelihood of osseointegration even in poor quality bone. 


\section{Conclusion}

The surface roughness is necessary for reliable and long term biomechanical fixation of dental implants. There are many types of surfaces available for titanium implants. But the development of such surface topographies has always been empirical. Effect of one surface treatment on the longevity and performance of dental implants over the other has not been properly studied. Controlled and standardized topography or chemistry of implant surface is necessary for comparative clinical studies. Thus future studies should aim in developing methods that could produce reproducible surface topography of dental implants.

\section{Conflict of Interest: No}

\section{References}

1. Le Guehennec L, Soueidan A, Layrolle P, Amouriq Y.Surface treatments of titanium dental implants for rapid osseointegration. Dent Mater. 2007;23(7):844-54.

2. Rosales-Leal JI, Rodríguez-Valverde MA, Mazzaglia G, Ramon-Torregrosa PJ et al.Effect of roughness, wettability and morphology of engineered titanium surfaces on osteoblast-like cell adhesion.Colloids and Surfaces A: Physicochemical and Engineering Aspects.2010;365(1-3):222-9.

3. Nakae H, Yoshida M, Yokota M.Effects of roughness pitch of surfaces on their wettability.J Mater Sci.2005;40(9):2287-93.

4. Sollazzo V, Pezzetti F, Scarano A, Piatelli A et al.Zirconium oxide coating improves implant osseointegration in vivo.Dent Mater.2008;24(3):357-61.

5. Cochran DL, Schenk RK, Lussi A, Higginbottom FL et al.Bone response to unloaded and loaded titanium implants with a sandblasted and acidetched surface: a histometric study in the canine mandible.J Biomed Mater Res A.1998;40(1): $1-11$.

6. Wennerberg A, Hallgren C, Johansson C, Danelli S.A histomorphometric evaluation of screw-shaped implants each prepared with two surface roughnesses.Clin Oral Implants Res.1998;9(1):11-9.
7. Brett PM, Harle J, Salih V, Mihoc R et al Roughness response genes in osteoblasts. Bone.2004;35(1):124-33.

8. Buser D, Schenk RK, Steinemann S, Fiorellini JP et al.Influence of surface characteristics on bone integration of titanium implants.A histomorphometric study in miniature pigs.J Biomed Mater Res A. 1991;25(7):889-902.

9. Becker W, Becker BE, Ricci A, Bahat O et al. A prospective multicenter clinical trial comparing one- and two-stage titanium screwshaped fixtures with one-stage plasma-sprayed solid-screw fixtures.Clin Implant Dent Relat Res.2000;2(3):159-65.

10. Hansson S, Norton M.The relation between surface roughness and interfacial shear strength for bone-anchored implants. A mathematical model.J Biomech.1999;32(8):829-36.

11. Jemat A, Ghazali MJ, Razali M, Otsuka Y. Surface modifications and their effects on titanium dental implants.BioMed research international 2015.

12. Shemtov-Yona K, Rittel D, Dorogoy A.Mechanical assessment of grit blasting surface treatments of dental implants.J Mech Behav Biomed Mater.2014;39:375-90.

13. Aparicio C, Gil FJ, Fonseca C, Barbosa M et al.Corrosion behaviour of commercially pure titanium shot blasted with different materials and sizes of shot particles for dental implant applications. Biomaterials.2003;24(2):263-73.

14. Rasmusson L, Roos J, Bystedt H.A 10year follow-up study of titanium dioxideblasted implants.Clin Implant Dent Relat Res.2005;7(1):36-42.

15. Wennerberg A, Albrektsson T, Andersson B, Krol JJ.A histomorphometric and removal torque study of screw-shaped titanium implants with three different surface topographies.Clin Oral Implants Res.1995;6(1):24-30.

16. Iwaya $\mathrm{Y}$, Machigashira $M$, Kanbara $K$, Miyamoto, $\mathrm{M}$ et al.Surface properties and biocompatibility of acid-etched titanium.Dent Mater J.2008;27(3):415-21.

17. Degidi M, Petrone G, Iezzi G, Piattelli A.Bone contact around acid-etched implants: a histological and histomorphometrical evaluation of two human-retrieved implants.J Oral Implantol.2003;29(1):13-8. 
18. Rupp F, Scheideler L, Olshanska N, de Wild $M$ et al.Enhancing surface free energy and hydrophilicity through chemical modification of microstructured titanium implant surfaces.J Biomed Mater Res A.2006;76(2):323-34.

19. Schwarz F, Herten M, Sager M, Wieland M et al.Histological and immunohistochemical analysis of initial and early osseous integration at chemically modified and conventional SLA titanium implants: preliminary results of a pilot study in dogs.Clin Oral Implants Res.2007;18(4):481-8.

20. Sul Y-T, Johansson CB, Jeong Y, Albrektsson T.The electrochemical oxide growth behaviour on titanium in acid and alkaline electrolytes. Med Eng Phy.2001;23(5):329-46.

21. Sul Y-T, Johansson CB, Röser K, Albrektsson T.Qualitative and quantitative observations of bone tissue reactions to anodised implants. Biomaterials.2002;23(8):1809-17.

22. Sul YT, Johansson CB, Jeong Y, Wennerberg $A$ et al.Resonance frequency and removal torque analysis of implants with turned and anodized surface oxides.Clin Oral Implants Res.2002;13(3):252-9.

23. Gaggl A, Schultes G, Muller WD, Karcher H.Scanning electron microscopical analysis of laser-treated titanium implant surfaces--a comparative study. Biomaterials.2000;21(10):1067-73.

24. Berardi D, Colagiovanni M, Scoccia A, Raffaelli $\mathrm{L}$ et al.Evaluation of a new laser surface implant: scanning electron microscopy/energy dispersive X-ray and X-ray photoelectron spectroscopy analyses.J Biol Regul Homeost Agents.2008;22(3):161-7.

25. Park CY, Kim SG, Kim MD, Eom TG et al.Surface properties of endosseous dental implants after NdYAG and $\mathrm{CO} 2$ laser treatment at various energies.J Oral Maxillofac Surg.2005;63(10):1522-7.

26. Ong JL, Chan DC. Hydroxyapatite and their use as coatings in dental implants: a review. Crit Rev Biomed Eng.2000;28(5-6):667-707.

27. Ong JL, Carnes DL, Bessho K.Evaluation of titanium plasma-sprayed and plasmasprayed hydroxyapatite implants in vivo. Biomaterials.2004;25(19):4601-6.

28. Morris HF, Ochi S, Spray JR, Olson JW.Periodontal-type measurements associated with hydroxyapatite-coated and non-HA- coated implants: uncovering to 36 months.Ann Periodontol.2000;5(1):56-67.

29. Wheeler SL. Eight-year clinical retrospective study of titanium plasma-sprayed and hydroxyapatite-coated cylinder implants.Int J Oral Maxillofac Implants.1996;11(3):340-50.

30. Meng X, Kwon TY, Kim KH. Hydroxyapatite coating by electrophoretic deposition at dynamic voltage.Dent Mater J.2008;27(5):66671.

31. Meng X, Kwon TY, Yang Y, Ong JL et al.Effects of applied voltages on hydroxyapatite coating of titanium by electrophoretic deposition.J Biomed Mater Res B Appl Biomater.2006;78(2):373-7.

32. Ding SJ.Properties and immersion behavior of magnetron-sputtered multi-layered hydroxyapatite/titanium composite coatings. Biomaterials.2003;24(23):4233-8.

33. Anselme K, Bigerelle M, Noel B, Iost A et al.Effect of grooved titanium substratum on human osteoblastic cell growth.J Biomed Mater Res A.2002;60(4):529-40.

34. Bigerelle M, Anselme K, Noel B, Ruderman $I$ et al.Improvement in the morphology of Ti-based surfaces: a new process to increase in vitro human osteoblast response. Biomaterials.2002;23(7):1563-77.

35. Zhu X, Chen J, Scheideler L, Altebaeumer $\mathrm{T}$ et al.Cellular reactions of osteoblasts to micron- and submicron-scale porous structures of titanium surfaces.Cells Tissue Organs.2004;178(1):13-22.

36. Josse S, Faucheux C, Soueidan A, Grimandi G et al. Chemically Modified Calcium Phosphates as Novel Materials for Bisphosphonate Delivery. Adv Mater. 2004;16(16):1423-7.

37. He FM, Yang GL, Li YN, Wang XX et al.Early bone response to sandblasted, dual acid-etched and $\mathrm{H} 2 \mathrm{O} 2 / \mathrm{HCl}$ treated titanium implants: an experimental study in the rabbit. Int $\mathrm{J}$ Oral Maxillofac Surg. 2009;38(6):677-81.

38. Elias CN, Meyers MA, Valiev RZ, Monteiro SN. Ultrafine grained titanium for biomedical applications: An overview of performance. J Mater Res Technol.2013;2(4):340-50

39. Singh RG. A comparative analysis of sandblasted and acid etched and polished titanium surface on enhancement of osteogenic potential: An in vitro study.J Dent Implant.2012;2(1):15-18 